\title{
Recovery of conduction velocity distal to a compressive lesion
}

\author{
PAMELA M. LE QUESNE AND E. B. CASEY \\ From the Department of Neurological Studies, The Middlesex Hospital, \\ and M.R.C. Toxicology Unit, Carshalton, Surrey
}

SYNOPSIS Nerve conduction studies have been carried out pre- and postoperatively on 26 hands of patients with a carpal tunnel syndrome. When examined six to eight weeks postoperatively, there had been no significant change in conduction velocity or action potential amplitude in the fingers distal to the compression. Velocity had increased over the carpal tunnel segment. When the patients were seen between 12 and 18 weeks postoperatively, velocity and amplitude had increased in the fingers. The group with marked electrical abnormalities had improved more than the group in which digital amplitude was originally within the control range. The improvement occurred too early to be due to regeneration after relief of compression. It is suggested that either maturation of regenerating fibres was delayed by the compression or a reversible change had occurred in surviving fibres.

Previous workers have found that conduction velocity may be reduced in nerve fibres distal to a chronic compressive lesion. In a proportion of patients with the carpal tunnel syndrome McLeod (1966), Buchthal and Rosenfalck (1971), and Casey and Le Quesne (1972) found a reduction of maximal velocity in the fingers, although the reduction in velocity was always more marked over the carpal tunnel segment.

McLeod (1966), using a mechanical tap on the finger nail as a stimulus, found that in addition to reduction in maximal velocity, there was often evidence of dispersion of the nerve action potential along the finger in carpal tunnel patients. Buchthal and Rosenfalk (1971) found that the minimum velocity of conduction from finger to palm was below the control range in a few of their patients. Both these observations suggest that actual slowing of conduction probably occurs in at least some of the fibres distal to the site of compression.

There have been few studies of changes in conduction in the distal segment of nerve after relief of the compression. McLeod (1966) studied one patient in whom conduction velocity in the finger was $21 \mathrm{~m} / \mathrm{s}$ preoperatively. When the median nerve was decompressed, conduction velocity increased to $29 \mathrm{~m} / \mathrm{s}$ after 18 weeks and
$38 \mathrm{~m} / \mathrm{s}$ after 42 weeks. Buchthal and Rosenfalck (1971) examined two patients at 10 and 1 . weeks after nerve compression was relieved an $\$$ found that maximum velocity had increased $b 8$ 7 and $9 \mathrm{~m} / \mathrm{sec}$. One further patient is describe by Buchthal et al. (1974) in whom maximun. velocity in the finger had increased from $46 \mathrm{~m} / \mathrm{s}^{+}$ to $52 \mathrm{~m} / \mathrm{s} 30$ days after operation.

The present study provides further data about the recovery of conduction in the digital nerves of patients in whom a carpal tunnel syndrome was treated surgically.

\section{METHODS}

PATIENTS Electrophysiological studies were carried out on 21 patients in whom a carpal tunnel syndrome was treated surgically. Five patients had operations on both wrists, making a total of 26 hands. The diagnosis was originally made clinically and confirmed by routine nerve conduction measurements. Tests were performed on all patients during the week before operation. Most were re-examined between six and eight weeks after the operation. All except one were seen between 12 and 18 weeks postoperatively.

One patient aged 22 years, who had a median nerve sutured after complete transection of the nerve at the wrist, was examined at intervals for up to one year postoperatively. 

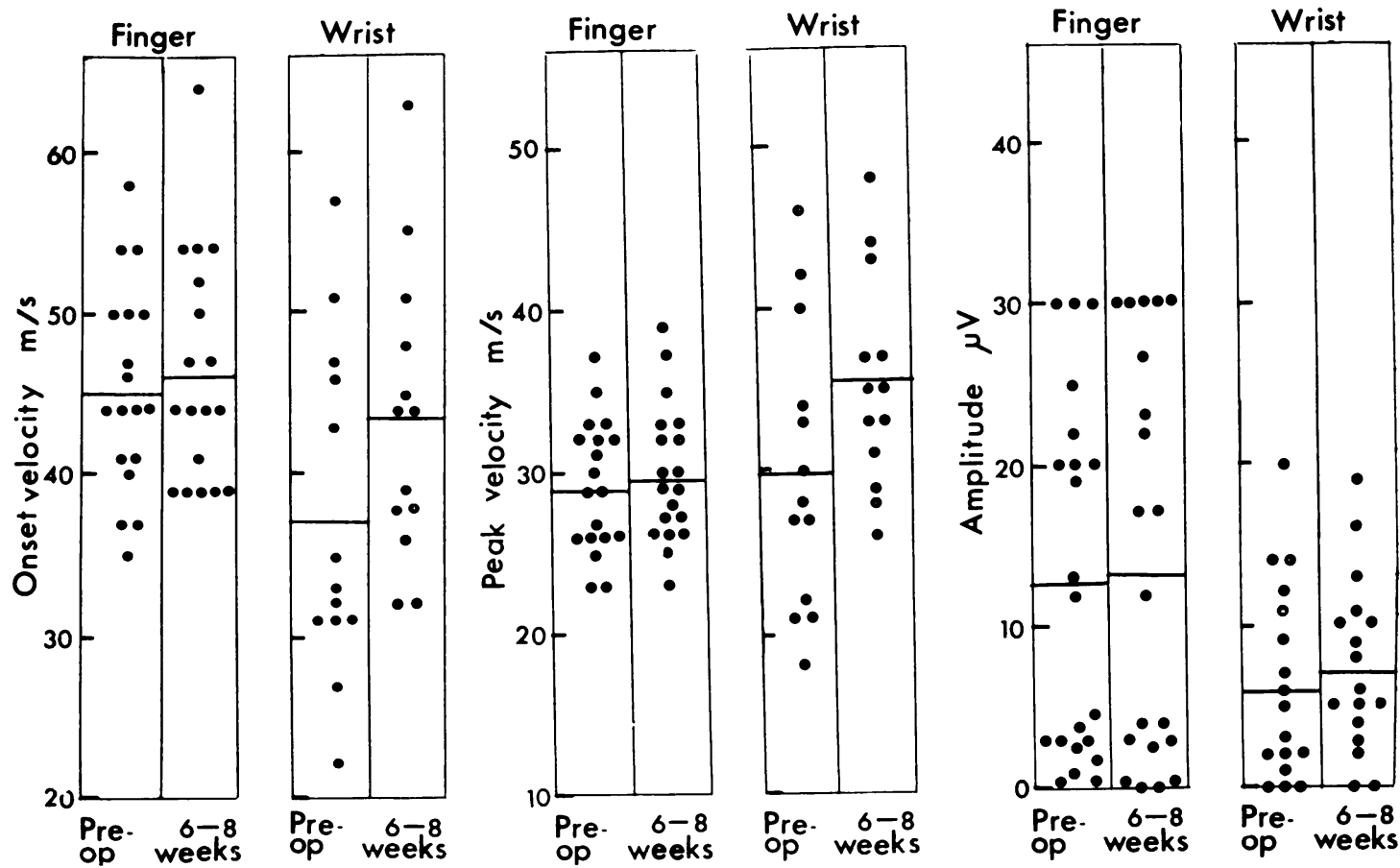

FIG. 1. Comparison of velocity and amplitude of finger and wrist potentials preoperatively and six to eight weeks postoperatively.

TABLE 1

SENSORY NERVE CONDUCTION STUDIES BETWEEN SIX AND EIGHT WEEKS POSTOPERATIVELY*

\begin{tabular}{|c|c|c|c|c|c|c|c|c|c|c|}
\hline & \multicolumn{5}{|c|}{ Finger } & \multicolumn{5}{|c|}{ Wrist } \\
\hline & $n$ & Preop. & $6-8$ weeks & $P$ & Control & $n$ & Preop. & 6-8 weeks & $P$ & Control \\
\hline $\begin{array}{l}\text { Onset velocity }(\mathrm{m} / \mathrm{s}) \\
\text { Peak velocity }(\mathrm{m} / \mathrm{s}) \\
\text { Amplitude }(\mu \mathrm{V})\end{array}$ & $\begin{array}{l}18 \\
19 \\
21\end{array}$ & $\begin{array}{l}45 \cdot 3 \pm 6 \cdot 4 \\
29 \cdot 2 \pm 4 \cdot 0 \\
12 \cdot 6 \pm 11 \cdot 0\end{array}$ & $\begin{array}{l}46 \cdot 3 \pm 7 \cdot 1 \\
29 \cdot 8 \pm 4 \cdot 3 \\
13 \cdot 8 \pm 12 \cdot 2\end{array}$ & $\begin{array}{l}>0.3 \\
>0.3 \\
>0.1\end{array}$ & $\begin{array}{l}54 \cdot 8 \pm 7 \cdot 3 \\
39 \cdot 9 \pm 3 \cdot 3 \\
33 \cdot 6 \pm 10 \cdot 6\end{array}$ & $\begin{array}{l}13 \\
13 \\
17\end{array}$ & $\begin{array}{c}37 \cdot 4 \pm 10 \cdot 4 \\
29 \cdot 9 \pm 8 \cdot 7 \\
6 \cdot 4 \pm 6 \cdot 0\end{array}$ & $\begin{array}{r}43 \cdot 5 \pm 9 \cdot 1 \\
35 \cdot 3 \pm 6 \cdot 5 \\
7 \cdot 4 \pm 5 \cdot 4\end{array}$ & $\begin{array}{l}<0.005 \\
<0.001 \\
>0.1\end{array}$ & $\begin{array}{c}-\overline{46} \pm 3 \cdot 6 \\
19 \cdot 8 \pm 6 \cdot 7\end{array}$ \\
\hline
\end{tabular}

* Mean and standard deviations shown and significance for paired $t$ test. Control values from Casey and Le Quesne (1972).

ELECTROPHYSIOLOGICAL METHODS A Medelec MS 3R electromyograph was used. At the initial examination the distal latency of muscle response for motor fibres supplying abductor pollicis brevis muscle was measured after stimulation of the median nerve at the wrist, the muscle action potential being recorded through a coaxial needle electrode. Postoperative studies of motor latency were not performed, the initial measurement being made to provide an indication of the severity of the median nerve lesion.
At each visit sensory action potential conductivity recordings were made over two segments of the median nerve-(a) from the tip to the base of the middle finger and (b) from the base of the middle finger to the wrist, the latter segment including the site of nerve compression.

In (a) digital nerve action potentials were recorded using the technique described by Casey and Le Quesne (1972). When stimulating and recording from the digital nerves of the fingers, interelectrode distance is small and precautions must be taken to 

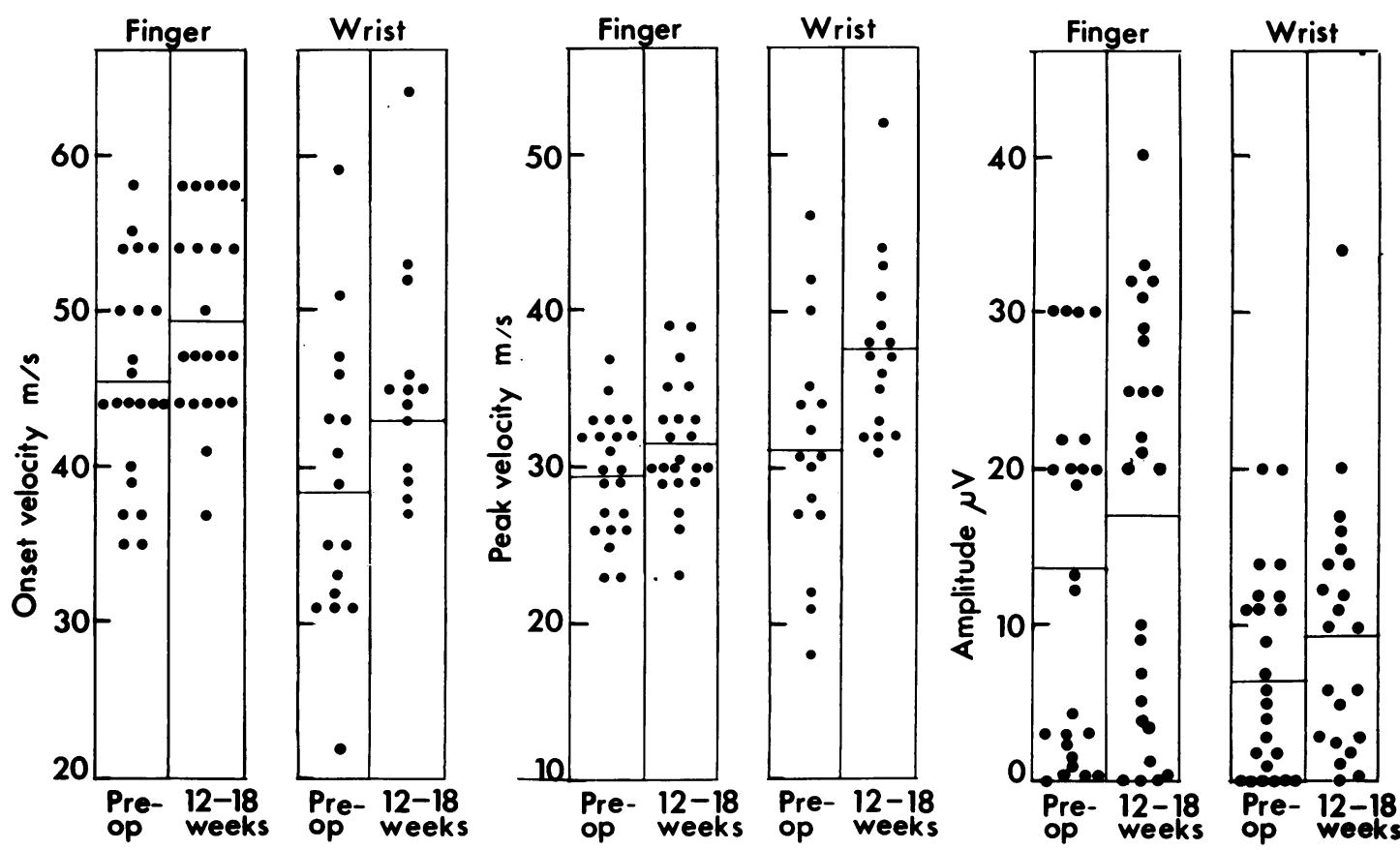

FIG. 2. Comparison of velocity and amplitude of finger and wrist potentials preoperatively and 12 to 18 weeks postoperatively.

ensure that the stimulator is well isolated from the recording apparatus. Details of the stimulator used, the method of applying wire electrodes round the finger, and the precautions necessary to maintain limb temperature are given by Casey and Le Quesne (1972). The digital nerves were stimulated at the tip of the middle finger and the sensory action potential was recorded at the base of the finger. The distance between stimulating and recording electrodes was $3.5 \mathrm{~cm}$ and the recording inter-electrode distance was kept constant at $1.5 \mathrm{~cm}$.

In (b) the digital nerves were stimulated at the base of the finger and the sensory nerve action potential was recorded at the wrist through surface saddle electrodes, $4 \mathrm{~cm}$ apart (Dawson, 1956).

The skin temperature at the tip of the finger was maintained between $34.5^{\circ} \mathrm{C}$ and $35^{\circ} \mathrm{C}$ throughout the nerve conduction recordings.

For recording sensory nerve action potentials at least 30 traces were fed into a 100 ordinate averager (Medelec AVM 3B/1). The averaged response was displayed on an oscilloscope and photographic records of the trace were obtained. For the calculation of conduction velocity, latency of evoked response was measured both to the onset of the first negative deflection from the base line (onset latency) and to the peak of the negative deflection (peak latency): Onset latency allows velocity to be calculated in the most rapidly conducting fibres. Peak latency includes the rise-time of the action potential and may therefore give an indication of dispersion. Amplitude was measured from peak to peak of the potential.

\section{RESULTS}

DISTAL MOTOR LATENCY In one of the 26 hands no muscle response to nerve stimulation could be obtained. In 12 instances distal motor latency was greater than $5.0 \mathrm{~ms}$, which has been taken as the upper limit of the control range (Thomas, 1960). The longest latency recorded was $10.5 \mathrm{~ms}$. In 12 cases distal latency was $5.0 \mathrm{~ms}$ or less. Motor studies were not performed on one patient. Thus, motor conduction was significantly abnormal in one half of the hands studied.

EXAMINATION AT SIX TO EIGHT WEEKS Digital nerve conduction studies were carried out in 21 
TABLE 2

SENSORY NERVE CONDUCTION STUDIES BETWEEN 12 AND 18 WEEKS POSTOPERATIVELY*

\begin{tabular}{|c|c|c|c|c|c|c|c|c|}
\hline & \multicolumn{4}{|c|}{ Finger } & \multicolumn{4}{|c|}{ Wrist } \\
\hline & $n$ & Preop. & $12-18$ weeks & $P$ & $n$ & Preop. & $12-18$ weeks & $P$ \\
\hline $\begin{array}{l}\text { Onset velocity }(\mathrm{m} / \mathrm{s}) \\
\text { Peak velocity }(\mathrm{m} / \mathrm{s}) \\
\text { Amplitude }(\mu \mathrm{V})\end{array}$ & $\begin{array}{l}22 \\
22 \\
25\end{array}$ & $\begin{array}{l}45 \cdot 7 \pm 6 \cdot 8 \\
29 \cdot 6 \pm 3 \cdot 8 \\
13 \cdot 3 \pm 11 \cdot 3\end{array}$ & $\begin{array}{l}49 \cdot 5 \pm 6 \cdot 4 \\
31 \cdot 4 \pm 3 \cdot 9 \\
16 \cdot 9 \pm 12 \cdot 9\end{array}$ & $\begin{array}{l}<0.005 \\
<0.02 \\
<0.001\end{array}$ & $\begin{array}{l}16 \\
16 \\
23\end{array}$ & $\begin{array}{r}38 \cdot 6 \pm 9 \cdot 0 \\
31 \cdot 2 \pm 7 \cdot 6 \\
6 \cdot 7 \pm 6 \cdot 5\end{array}$ & $\begin{array}{r}46 \cdot 2 \pm 6 \cdot 8 \\
37 \cdot 5 \pm 5 \cdot 5 \\
9 \cdot 8 \pm 7 \cdot 9\end{array}$ & $\begin{array}{l}<0.001 \\
<0.001 \\
<0.005\end{array}$ \\
\hline
\end{tabular}

* Mean and standard deviations shown, and significances for paired $t$ test.

of the 26 cases preoperatively and between six and eight weeks postoperatively. In 17 cases, attempts were also made to record the sensory potential at the wrist. The results are shown in Fig. 1 and Table 1. Each set of data consists of paired observations for pre- and postoperative recordings. When a potential could be recorded on only one of the two occasions, data for amplitude but not for velocity have been included.

Comparisons have been made between the pre- and postoperative findings and the significance of the difference tested by using the paired $t$ test. The results are shown in Table 1 . It can be seen that there is no significant difference for any of the parameters measured for the finger potential. There was, however, a significant increase in velocity over the wrist segment when estimated from latency measurements to the onset and to the peak of the potential recorded at the wrist. Mean onset velocity had increased from $37.4 \mathrm{~m} / \mathrm{s}$ to $43.5 \mathrm{~m} / \mathrm{s}$ and mean peak velocity from $29.9 \mathrm{~m} / \mathrm{s}$ to $35.3 \mathrm{~m} / \mathrm{s}$. There had been no significant increase in the amplitude of the wrist potential.

In 12 of the 21 hands the amplitude of the digital potential was below the lower limit $(18 \mu \mathrm{V})$ of the control values found by Casey and Le Quesne (1972). When the findings in these hands were considered separately, there was still no significant difference between the preoperative and six weeks postoperative results.

EXAMINATION AT 12-18 weEks Twenty five examinations were carried out preoperatively and over this period. The results are shown in Fig. 2 and Table 2. Again paired observations have been used in all instances. It can be seen that the mean values for onset and peak velocities had increased for both the digital and wrist potentials. Onset velocity for the finger potential had increased from a mean value of $45.7 \mathrm{~m} / \mathrm{s}$ to $49.5 \mathrm{~m} / \mathrm{s}$. Onset velocity for the wrist potential had increased by a greater amount $(38.6 \mathrm{~m} / \mathrm{s}$ to $46.2 \mathrm{~m} / \mathrm{s}$.)

The amplitudes of both digital and wrist potentials had increased. The mean value for the finger action potential had increased from 13.3 $\mu \mathrm{V}$ to $16.9 \mu \mathrm{V}$ and the wrist potential had increased from $6.7 \mu \mathrm{V}$ to $9.8 \mu \mathrm{V}$.

The difference between preoperative and postoperative recordings was statistically significant

TABLE 3

SENSORY NERVE CONDUCTION STUDIES FOR FINGER POTENTIAL BETWEEN 12 AND 18 WEEKS POSTOPERATIVELY*

\begin{tabular}{|c|c|c|c|c|c|c|c|c|}
\hline & \multicolumn{4}{|c|}{ Reduced amplitude } & \multicolumn{4}{|c|}{ Normal amplitude } \\
\hline & $n$ & Preop. & 12-18 weeks & $\boldsymbol{P}$ & $n$ & Preop. & 12-18 weeks & $P$ \\
\hline $\begin{array}{l}\text { Onset velocity }(\mathrm{m} / \mathrm{s}) \\
\text { Peak velocity }(\mathrm{m} / \mathrm{s}) \\
\text { Amplitude }(\mu \mathrm{V})\end{array}$ & $\begin{array}{l}10 \\
10 \\
13\end{array}$ & $\begin{array}{r}41 \cdot 3 \pm 5 \cdot 9 \\
27 \cdot 0 \pm 3 \cdot 3 \\
3 \cdot 5 \pm 4 \cdot 2\end{array}$ & $\begin{array}{r}47 \cdot 4 \pm 7 \cdot 1 \\
29 \cdot 3 \pm 3 \cdot 8 \\
6 \cdot 4 \pm 7 \cdot 3\end{array}$ & $\begin{array}{l}<0.005 \\
<0.05 \\
<0.05\end{array}$ & $\begin{array}{l}12 \\
12 \\
12\end{array}$ & $\begin{array}{l}49 \cdot 3 \pm 5 \cdot 3 \\
31 \cdot 8 \pm 2 \cdot 8 \\
24 \cdot 0 \pm 4 \cdot 7\end{array}$ & $\begin{array}{l}51 \cdot 3 \pm 5 \cdot 4 \\
33 \cdot 2 \pm 3 \cdot 3 \\
28 \cdot 3 \pm 5 \cdot 6\end{array}$ & $\begin{array}{l}>0.2 \\
>0.2 \\
<0.01\end{array}$ \\
\hline
\end{tabular}

* Mean and standard deviations shown. 
by the paired $t$ test for all the parameters measured for both the finger and the wrist potentials (Table 2).

Table 3 shows the results of analysing separately the hands in which the amplitude of the finger potential was reduced below the control range $(18 \mu \mathrm{V})$ preoperatively and those in whom it was within control limits. It can be seen that there was a greater change postoperatively in those with the more abnormal findings. The small increase in velocity in those with the larger potentials was not significant, although there was a significant increase in amplitude.

RESULTS OF NERVE SUTURE The patient who had a complete transection of his median nerve at the wrist was examined four, eight, and 12 months postoperatively. No potential could be recorded from the finger at four or eight months. After 12 months a small potential of $4 \mu \mathrm{V}$ was recorded. Onset velocity was $29 \mathrm{~m} / \mathrm{s}$ and peak velocity was $19 \mathrm{~m} / \mathrm{s}$.

\section{DISCUSSION}

The present results have shown that a significant increase in sensory nerve conduction velocity and action potential amplitude occurred in the segment of nerve distal to the carpal tunnel within three months of relief of the compression. No change was evident at six weeks. The recovery could not have been due to regeneration of nerve fibres from the level of compression. On the basis of a possible growth rate of $2 \mathrm{~mm} /$ day starting immediately after decompression, one would expect 60 days to elapse before the growing tips of nerve fibres reached the stimulating cathode, situated about $12 \mathrm{~cm}$ from the distal edge of the flexor retinaculum. But at this time the threshold of the regenerated fibres would be so high that they would not be stimulated through the skin. Velocity at this stage would also be low. On theoretical grounds, it does not seem possible that newly regenerated fibres could conduct at over $45 \mathrm{~m} / \mathrm{s}$ in the finger within three months of operative decompression at the wrist. More direct evidence that regeneration did not cause the increases in velocity that we have observed is provided by the patient whose median nerve was sutured at the wrist. No finger potential could be recorded eight months postoperatively, and, after a year, when a small potential was recorded, maximal velocity was $\stackrel{=}{=}$ only $29 \mathrm{~m} / \mathrm{s}$. We conclude that some process 0 other than regeneration is responsible for the early improvement in our carpal tunnel patients.

These findings raise some interesting questions $\stackrel{\text { F }}{2}$ as to what is happening pathologically. Thomas and Fullerton (1963) examined the digital nerves $\stackrel{\oplus}{\stackrel{9}{+}}$ from a patient with a carpal tunnel syndrome and found considerable reduction in the proportion $\frac{\bar{\sigma}}{\bar{N}}$ of large diameter fibres. However, total fibre number was not available and so it is difficult to say to what extent the changes might have been due to Wallerian degeneration.

Changes in paranodal myelin have been described both proximal and distal to chronic compressive lesions. In the median nerve lesion of old guinea-pigs, Ochoa and Marotte (1973) found bulbous myelin swellings at one end of af internode with progressive tapering of myelifi $\vec{N}$ along the internode. These changes, which were $\vec{\omega}$ limited to one or two centimetres from the site of compression, were followed by paranodpip demyelination. Similar bulbous swellings, with or without paranodal demyelination, have been seen in human nerves adjacent to sites oळ $\underset{\mathbb{\Phi}}{\Phi}$ entrapment (Neary et al., 1974). It is doubtfuk. however, whether such changes extend fáf enough distally to explain the electrophysio- $\overrightarrow{0}$ logical changes that we have described.

A possible explanation for the early recovery of velocity might be that some fibres have degenerated and regenerated from the site of compression, but that full maturation was not able to occur until the compression was relieved. This possibility was originally suggested by Weiss and Hiscoe (1948) as an explanation for the absence of large diameter fibres in nerves which had regenerated through a constricted region. Indeed, there is some evidence that degeneration followed by regeneration may occur in some fibres distal to a chronic compressive lesion in spite of continuing compression. Marotte (1974) found axonal clusters suggesting that regeneration was occurring in sections of nerves distal to the site of compression in old guinea-pigs. Thus, the carpal tunnel syndrome may provide an example of the impeded regeneration originally described by Weiss and Hiscoe (1948).

Bauwens (1968) used the term 'axonocachexia' 
to explain some of the changes distal to a chronic compressive lesion. He suggested that there might be attenuation of fibre diameter distal to a compressive lesion not only in regenerating but also in surviving fibres as a result of reduced axoplasmic flow through the compressed region. This phenomenon was also described by Weiss and Hiscoe (1948) but thought to be less important than the effect of constriction on regenerating fibres. There is at present no histological evidence available from human cases to support or refute the suggestion that reduced axoplasmic flow leads to attenuation of fibre diameter or affects conduction velocity in the carpal tunnel syndrome.

Some of the changes distal to a compressive lesion must be attributed to Wallerian degeneration, which is known to occur in severe lesions (Fullerton and Gilliatt, 1967). Since the largest diameter fibres are most likely to be damaged by compression (Gelfan and Tarlov, 1956; Marotte, 1974), reduction in maximum velocity will result from degeneration of some fibres. The present studies, however, have shown that there is additionally some other change which is reversible within three months of relieving the compression. Whether this is caused by delayed maturation of regenerating fibres or a change in surviving fibres can be decided only after further work, particularly detailed histological studies of the fibres distal to a compressed zone.

We would like to thank Mr. J. C. A. Madgwick for permission to examine the patient after median nerve suture. We are also grateful to Professor R. W. Gilliatt for his helpful comments.

\section{REFERENCES}

Bauwens, P. (1960). Electrodiagnostic definition of the site and nature of peripheral nerve lesions. Annals of Physical Medicine, 5, 149-152.

Buchthal, F., and Rosenfalck, A. (1971). Sensory conduction from digit to palm and from palm to wrist in the carpal tunnel syndrome. Journal of Neurology, Neurosurgery, and Psychiatry, 34, 243-252.

Buchthal, F., Rosenfalck, A., and Trojaborg, W. (1974). Electrophysiological findings in entrapment of the median nerve at wrist and elbow. Journal of Neurology, Neurosurgery, and Psychiatry, 37, 340-360.

Casey, E. B., and Le Quesne, P. M. (1972). Digital nerve action potentials in healthy subjects, and in carpal tunnel and diabetic patients. Journal of Neurology, Neurosurgery, and Psychiatry, 35, 612-623.

Dawson, G. D. (1956). The relative excitability and conduction velocity of sensory and motor nerve fibres in man. Journal of Physiology, 131, 436-451.

Fullerton, P. M., and Gilliatt, R. W. (1967). Median and ulnar neuropathy in the guinea-pig. Journal of Neurology, Neurosurgery, and Psychiatry, 30, 393-402.

Gelfan, S., and Tarlov, I. M. (1956). Physiology of spinal cord, nerve root and peripheral nerve compression. American Journal of Physiology, 185, 217-229.

McLeod, J. G. (1966). Digital nerve conduction in the carpal tunnel syndrome after mechanical stimulation of the finger. Journal of Neurology, Neurosurgery and Psychiatry, 29, 12-22.

Marotte, L. R. (1974). An electron microscope study of chronic median nerve compression in the guinea-pig. Acta Neuropathologica (Berl.), 27, 69-82.

Neary, D., Ochoa, J., and Gilliatt, R. W. (1974). Subclinical entrapment neuropathy in man. Paper submitted to $\mathrm{VII}^{\mathrm{th}}$ International Congress of Neuropathology, Budapest, 1974. Journal of the Neurological Sciences. (In press.)

Ochoa, J., and Marotte, L. (1973). The nature of the nerve lesion caused by chronic entrapment in the guinea-pig. Journal of the Neurological Sciences, 19, 491-495.

Thomas, P. K., and Fullerton, P. M. (1963). Nerve fibre size in the carpal tunnel syndrome. Journal of Neurology, Neurosurgery and Psychiatry, 26, 520-527.

Weiss, P., and Hiscoe, H. B. (1948). Experiments on the mechanism of nerve growth. Journal of Experimental Zoology, 107, 315-395. 